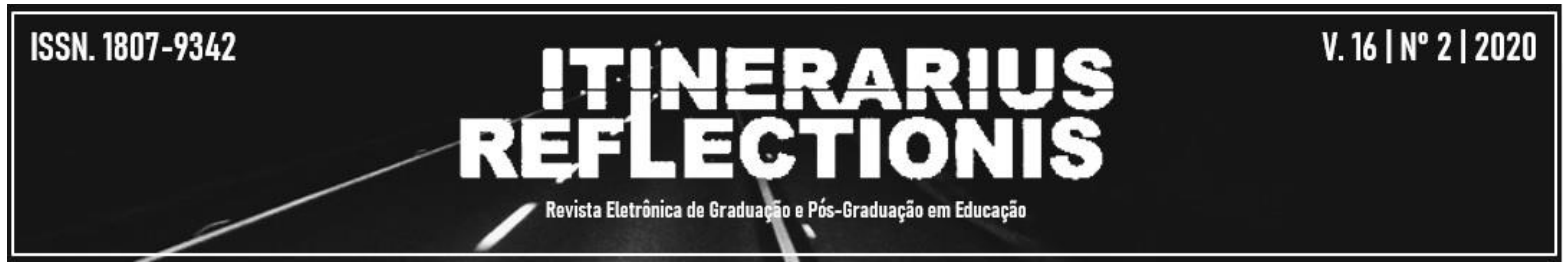

\title{
O resgate da categoria ideologia em György Lukács em fomento à reivindicação práxica das teorias críticas da educação
}

\author{
Júlio César Apolinário Maia ${ }^{1}$
}

\begin{abstract}
Resumo: Da necessidade de se ater ao caminho traçado pelas teorias críticas da educação, ao valeremse das ideias propostas por uma série de teóricos estudiosos do pensamento de Marx, pode ser apreendida a objetivação do presente estudo. Para tanto busca tornar evidente, a partir da concepção de escola conjecturada por este teórico, a singularidade concebida à exposição da categoria ideologia, alvo de aprofundamento por grande parte de seus sucessores, como é o caso de Lukács, mote do presente arrazoado. $\mathrm{O}$ húngaro avança no sentido de conceber reconhecimento à ideologia enquanto campo fértil ao desenvolvimento dos interesses sociais coletivos, comuns e universais. O esforço de síntese do estudo enfatiza como se torna possível, a partir do avanço propiciado por Lukács para com a categoria ideologia, não limitá-la tão somente à ação teleológica laborativa, mas avançar a partir da dupla possibilidade calcada no âmbito da ação teleológica extra-laborativa. Conclui, por conseguinte, trazendo à tona a ideia de que a partir do sentido extra-laborativo a ação teleológica pode ser compreendida enquanto princípio educativo. Desta forma, ao pressupor a negação de uma ideologia hegemônica, tanto no que concerne a realidade material, quanto no campo da consciência, conjecturase sua substituição por outra atinente à transformação da realidade material.
\end{abstract}

Paravras-chave: Ideologia. Lukács. Teoria crítica da educação.

\section{Ideology category rescue in György Lukács as foment to the praxical claim of education critical theories}

Abstract: From the necessity to stick to the way traced by the education critical theories, using a lot of theoreticians of Marx's ideas, can be visible a present study objectivation. Then it seeks to make evident, from the school conception conjectured by this theorist, the singularity conceived in ideology category, object to great part of its successors, like Lukács, mote of the present text. The Hungarian advances towards the recognition of ideology as a fertile field for the collective, common and universal social interest's development. The synthesis effort of the study emphasizes how it becomes possible, starting from Lukács's advance towards the ideology category, not limit it only to the laborative teleological action, but advance from the double possibility based on the extra laborative teleological action. It concludes bringing to surface the idea the extra laborative teleological action can be understood as an educational principle. Then presupposing the hegemonic ideology denial, both as regards material reality and in the consciousness field, its substitution is conjectured by another one related to the concret reality transformation.

Key-words: Ideology. Lukács. Education critical theory.

\footnotetext{
${ }^{1}$ Licenciado em Educação Física pela Universidade Estadual de Goiás - Campus Goiânia ESEFFEGO (UEGESEFFEGO). Mestrando em Educação pela linha de pesquisa Formação Humana e Fundamentos da Educação do Programa de Pós-Graduação em Educação da Universidade Federal de Goiás - Regional Jataí (UFG-REJ). jcesarm@outlook.com.
} 


\section{CONSIDERAÇÕES INICIAIS: EM DEFESA DA "RESSURREIÇÃO DOS MORTOS"2}

É do esforço de tornar evidente a formulação do pensamento de uma teoria verdadeiramente crítica da educação ${ }^{3}$ (SAVIANI, 1995), e consequentemente pelo compromisso firmado em favor de uma concepção de educação que vislumbre a superação da sociedade de classes, ou seja, pela emancipação de uma consciência de classe revolucionária (ROSSLER, 2004), que deparamo-nos com uma série de postulados que, ao longo da história, buscaram fundamentar, em respaldo à ótica marxiana, as bases de uma concepção socialista de escola.

A intencionalidade deste arrazoado, portanto, é ater-se ao caminho traçado pelas teorias críticas da educação ao valerem-se das ideias propostas por uma série de teóricos estudiosos do pensamento de Marx. Para tanto se mostra evidente, a partir da concepção de escola conjecturada por este teórico, a singularidade concebida à exposição da categoria ideologia, alvo de aprofundamento por grande parte de seus sucessores ${ }^{4}$. Acredita-se que este resgate, em tempos de obscurantismo beligerante (DUARTE, 2018) ao cenário educacional, demarcado exclusivamente pelo fetichismo da individualidade, ou seja, pela expansão da alienação individual - na medida em que o próprio indivíduo opta pela despersonalização e pela impossibilidade do desenvolvimento livre de sua capacidade humana - é de fundamental importância à (re)conscientização das massas em prol do enriquecimento social das forças humanas.

O movimento de elevação cultural das massas é, pois, de fundamental importância para a materialização de uma perspectiva de educação que almeje o desenvolvimento da classe revolucionária (ROSSLER, 2004). É deste movimento que para Marx e Engels (2007) se faz surgir uma brecha à revolução, ou seja, a partir dos limites, impostos pelas relações de produção, sobre o pleno desenvolvimento das forças materiais humanas.

\footnotetext{
${ }^{2}$ Termo alusivo à Duarte (2016), ao defender "que os clássicos das ciências, das artes e da filosofia são sínteses ricas de atividade humana condensada, em estado de repouso, que deve ser trazida novamente à vida [...]" (contracapa).

${ }^{3}$ Diferentemente das Teorias crítico-reprodutivistas, que enxergam os determinantes sociais somente pela ótica da reflexão/reprodução, uma teoria verdadeiramente crítica da educação não pressupõe o papel da escola como o de reproduzir da complexidade e a contradição instaurada socialmente, mas o de viabilizar sua transformação/modificação (SAVIANI, 1995).

4 A categoria ideologia pode ser apercebida, por exemplo, em Lenin (1870-1924), György Lukács (1885-1971), Antonio Gramsci (1891-1937), Max Horkheimer (1895-1973), Theodor Adorno (1903-1969), Louis Althusser (1918-1990), Michael Löwy (1938), Terry Eagleton (1943), Slavoj Žižek (1949), dentre outros.
} 


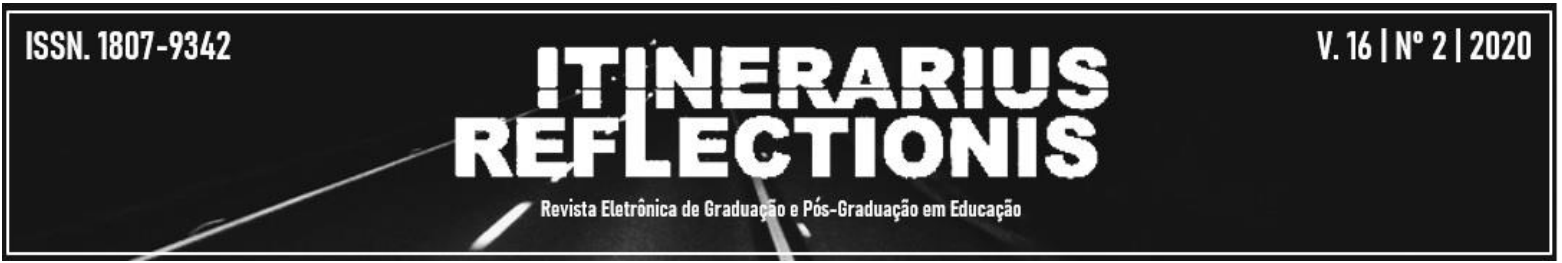

Se para esta dupla a negação e superação do completo estado de alienação passível de ser observado na desarticulação do trabalho e sua dimensão ontológica pressupõe uma dupla investida, ou seja, tanto sobre a necessidade de transformação da realidade material quanto pela necessidade de transformação da consciência em prol da transformação das bases materiais, acredita-se que por meio da explicitação das contradições, apercebidas no conjunto de formulações traçadas pelos teóricos estudiosos do pensamento de Marx, efetivadas pelo próprio capital na prospectiva de se auto-retificar, largos passos podem ser dados em direção à práxis transformadora, e consequentemente o solo ao estado revolucionário pode ser tornar cada vez mais fértil.

Vale partir, por hora, da interlocução posta sobre a própria concepção de educação indiretamente delineada por Marx, para que seja compreendida a pertinência traçada por este estudo com relação à categoria ideologia, como também sua pertinência para se pensar o cenário educacional que tanto assola a sociedade civil moderna. Em seguida a intencionalidade do artigo se detém às reflexões de Lukács no que tange o papel ideológico.

Acredita-se que este movimento pode (e deve) ser feito a partir de muitos outros estudiosos que se dedicaram à apreensão das ideias Marx. A escolha do húngaro, entretanto, deu-se exclusivamente pelo avanço à noção desta categoria, de origem marxiana, à relação para com outra categoria, aquela fundante do ser social: o trabalho. Reconhecendo, desta forma, a ideologia enquanto campo fértil ao desenvolvimento dos interesses proletários (da classe trabalhadora), Lukács tem papel fundamental para que possamos compreender, à luz do trabalho, em sua forma de ação teleológica extra-laborativa, a educação como veículo de emancipação dos grupos menos favorecidos aos interesses particulares e restritos dos grupos sociais hegemônicos e, em contrapartida, o reconhecimento dos interesses sociais coletivos, comuns e universais.

Para reconhecimento do avanço encontrado pelo húngaro, passa a ser adotada neste artigo a seguinte linha de raciocínio: i) a viabilidade de uma escola socialista, do ponto de vista da ótica marxiana, para se compreender a importância de contrafogo à ideologia do Estado burguês (em termos contemporâneos: de uma teoria crítica da educação que confronte os interesses econômicos vigentes); ii) a compreensão preliminar (e pessimista) dada por Marx à categoria ideologia e; iii) o avanço desta categoria, do ponto de vista da ótica lukáciana, em prol da consolidação de uma crítica que faça jus ao enriquecimento social das forças humanas. 


\title{
2 A CONCEPÇÃO DE ESTADO E IDEOLOGIA EM ATEIO À CRÍTICA PELA ESCOLA SOCIALISTA
}

A escola enquanto mantenedora do papel politico-ideológico cerceador dos interesses econômicos concernentes ao sistema capitalista, logo capacitada à reprodução tanto das relações de produção quanto das de exploração deste sistema, já era recriminada pelas cogitações de Marx e Engels no próprio Manifesto do Partido Comunista, originalmente publicado no final do Século XIX. Nesta passagem há uma crítica avessa às considerações burguesas em relação à educação comunista, ou seja, uma condenação da escola capitalista reprodutora das relações sociais:

\begin{abstract}
Recriminai-nos por querermos suprimir a exploração das crianças pelos pais? Efetivamente, denunciamos esse crime. Mas dizeis que suprimimos as relações mais íntimas substituindo a educação familiar pela educação social. Mas também vossa educação não está determinada pela sociedade? Pelas relações sociais em que a realizais, pela intromissão direta ou não da sociedade pelo viés da escola etc.? Os comunistas não inventam a ação da sociedade sobre a educação; apenas modificamlhe o caráter, subtraindo a educação da influência da classe dominante (MARX; ENGELS, 2017, p. 54, grifo meu).
\end{abstract}

Marx e Engels, apesar de não terem se ocupado veementemente do contexto educacional em suas obras, buscaram consolidar uma proposta de escola aos moldes socialistas. Tais moldes, a partir da análise de Manacorda (2007, p. 36) sobre os "Princípios do comunismo", impressos primordialmente por Engels (em novembro de 1847) e materializados um ano depois no próprio Manifesto do Partido Comunista, se relacionam à "adoção de medidas imediatas destinadas diretamente a atacar a propriedade privada e a garantir a existência do proletariado". Para se compreender esta defesa, favorável a uma política escolar que garanta a existência da classe proletária, Manacorda (2007) recorre aos princípios oitavo e décimo expressos no Manifesto:

8. Obrigatoriedade do trabalho para todos, organização de exércitos industriais, em especial para a agricultura [...];

10. Educação pública e gratuita para todas as crianças. Supressão do trabalho infantil em fábrica, em sua forma atual. Combinação da educação com a produção material (MARX; ENGELS, 2017, p. 61).

É retratado nestes princípios um requerimento não somente para o caráter democrático relativo à gratuidade e universalidade do ensino, mas um sabor socialista em 


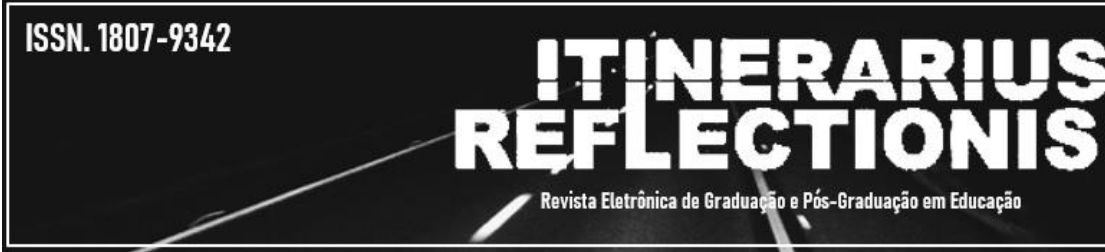

detrimento a conciliação do ensino com o trabalho ${ }^{5}$. Desta forma, a emancipação humana pode ser enunciada a partir da emancipação proletária, o que reforça a afirmativa de Jesus (2005) ao salientar que o marxismo não busca operar a partir de um marco zero, como uma tábula rasa a abrir caminhos, mas transformar prévios elementos já contidos e vinculados a uma realidade existente.

A educação socialista, excepcionalmente proposta no Manifesto do Partido Comunista, deve ser pensada a partir de sua prerrogativa por um sistema de ensino que busque beneficiar todos os homens. As etapas constituintes a esta educação deve se comportar de forma antagônica à ideologia do Estado Burguês, tendo em vista intentarem tanto a libertação das incumbências da propriedade privada, quanto a extinção da sociedade de classes e, consequentemente, da divisão do trabalho.

Neste sentido a concepção marxista de Estado, uma vez que o Estado Burguês confronta a edificação de uma educação aos moldes socialistas, deve ser levada em consideração para que se mostre evidente o caminho traçado pelas teorias verdadeiramente críticas da educação. Marx e Engels (2007, p. 75), ao considerar historicamente uma conversão de valores atribuídos à "propriedade", teorizam acerca do delineamento percorrido pelo Estado até se estabelecer enquanto "moderno".

Entre os povos originados da Idade Média, a propriedade tribal desenvolve-se passando por diferentes fases - propriedade feudal da terra, propriedade mobiliária corporativa, capital manufatureiro - até [...] chegar à propriedade privada pura, que se despiu de toda aparência de comunidade e suprimiu toda influência do Estado sobre o desenvolvimento da propriedade. A essa propriedade privada moderna corresponde o Estado moderno que, comprado progressivamente pelos proprietários privados por meio dos impostos, [...] tornou-se inteiramente dependente do crédito comercial que lhe é concedido pelos proprietários privados, os burgueses. [...] Por meio da emancipação da propriedade privada em relação à comunidade, o Estado se tornou uma existência particular ao lado e fora da sociedade civil; mas esse Estado não é nada mais do que a forma de organização que os burgueses se dão necessariamente, tanto no exterior como no interior, para a garantia recíproca de sua propriedade e de seus interesses (grifos meus).

Esta citação sugere uma concepção de Estado enquanto instrumento de manutenção suprema da classe dominante, portanto um aparelho que se vincula a conservação do quadro exploratório da classe burguesa sobre o proletariado. Existe a necessidade de

\footnotetext{
${ }^{5}$ Marx e Engels (2017), ao sugerirem tal conciliação, incentivavam à aplicação de uma mesma educação aos filhos de proletários e burgueses. A educação perspectivada aqui, portanto, é imbuída de validade universal e se relaciona a medidas tanto imediatas quanto porvindouras, deixando de se reter à índole contingente e limitada dos moldes da escola capitalista que tanto criticam
} 


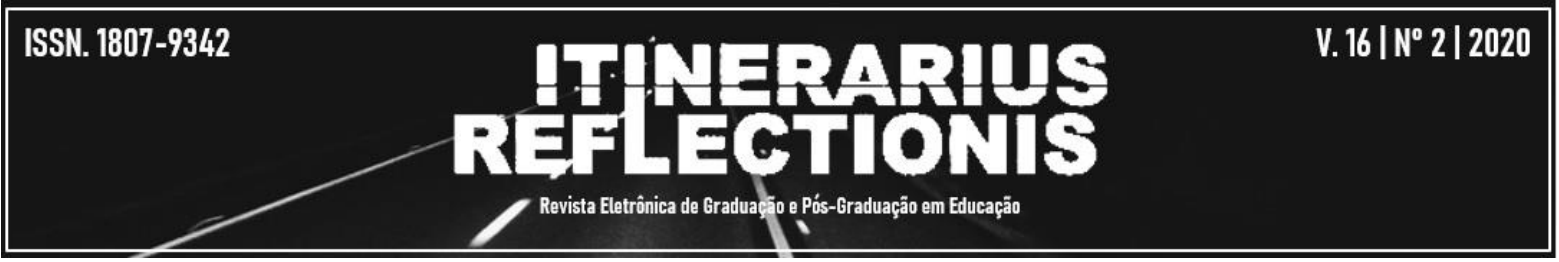

orientar-se a outro conceito, todavia, para que a compreensão do percurso percorrido pelas teorias críticas da educação estabeleça maior consistência, qual seja: o conceito de ideologia.

A objetivação, pois, a que vale este artigo, se vincula à compreensão deste conceito a partir de Lukács, um dos principais estudiosos do pensamento marxista. A apreensão acerca do papel ideológico exercido pela classe dominante a fim de que haja uma naturalização da realidade aos olhos da classe proletária é capital ao ponto de vista das análises marxianas, assim como, na prospectiva de um estudo subsequente, às reflexões críticas centradas ao campo educacional e pedagógico.

\section{A CONCEPÇÃO DE IDEOLOGIA SOB A ÉGIDE DO PENSAMENTO DE MARX: A "CÂMARA ESCURA"}

O primeiro período característico à compreensão do papel ideológico está nas próprias formulações de Marx, que o entende enquanto uma interpretação deformada da realidade, uma consciência equivocada e falsa que insiste em tomar o papel das ideias em modelar a materialidade dos homens. "[...] De maneira mistificada, fantasmagórica, enviesada, as ideologias expressam situações e interesses radicados nas relações materiais, de caráter econômico, que os homens, agrupados em classes sociais, estabelecem entre si" (GORENDER, 2013, p. 30). Não se caracterizam, portanto, enquanto ideia absoluta, capacitada à modificação e transformação da realidade social.

É importante compreender que a produção de ideias se relaciona intimamente à atividade material dos homens, caracterizando-se enquanto linguagem da vida real. $\mathrm{O}$ que Marx e Engels (2007, p. 94) denominam ideologia, portanto, é a inversão da relação existente entre a produção de ideias e a atividade material humana, tal qual uma ocorre numa "câmara escura". Ademais há de se compreender que o papel ideológico se resulta do processo de vida histórico da humanidade, "da mesma forma como a inversão dos objetos na retina resulta de seu processo de vida imediatamente físico" (MARX; ENGELS, 2007, p. 94). Assim, a atividade material humana se relaciona ao processo produtivo das ideias, todavia, também os homens se condicionam a um desenfreado desenvolvimento das forças produtivas que acaba por influenciar diretamente nas formas com que as ideias podem adotar, fomentando o papel ideológico.

Chauí (1988) reforça este entendimento ao salientar que, em busca do domínio sobre as ideias, a classe dominante detentora explícita dos meios de produção (econômico, 


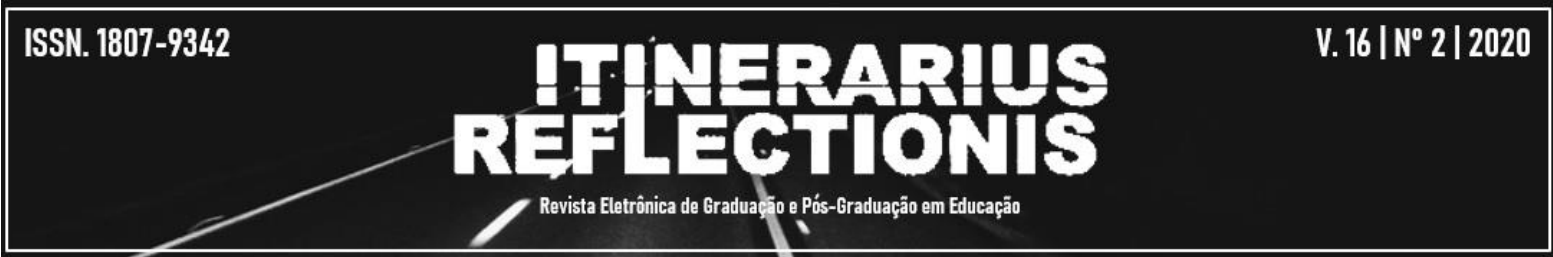

social e político), precisamente transforma suas ideias em conceitos influentes à sociedade como um todo. Estabelece ainda quatro elementos fundamentais para a materialização deste cenário: a divisão social de classes, ao subsidiar a dominação de uma classe sobre a outra; a falta de percepção dos membros da sociedade acerca da própria divisão social de classes que a eles é instaurada; a edificação e distribuição das ideias dominantes através de veículos religiosos, educacionais, midiáticos, etc.; a consolidação das ideias dominantes à realidade concreta, que verdadeiramente se apresentam enquanto aparência a esta realidade.

Admitir justiça à existência da mais valia ${ }^{6}$, via de exemplo, assim como qualquer outra adversidade da sociedade capitalista, é peculiaridade da força exercida pelo papel ideológico da classe dominante. Conde (1999, p. 40) ironicamente complementa este entendimento ao questionar a existência de algo "mais natural que o dono dos meios de produção comprar a mão-de-obra que está sendo ofertada por um preço baixo”. O bordão “o trabalho dignifica o homem”, muito bem lembrado por Chaú (1988), se apresenta como uma amostra ao papel ideológico enquanto dissimulador da realidade, a ele cabe uma reflexão acerca do quão o homem se mostra ludibriado ao vender sua força de trabalho de forma desvalida e, concomitantemente, creditar sentido de justiça e honestidade para consigo e para com a sociedade.

Em Marx, o conceito de ideologia possibilita enxergar a atribuição dada a classe trabalhadora para que, diante de uma falsa consciência da realidade se interesse economicamente, politicamente e socialmente por valores mantenedores da eficácia e supremacia da classe burguesa. Codato (2016) enxerga ser propício, o conceito de ideologia em Marx, para se descrever a ação de determinadas doutrinas (ou pensamentos) que se promovem enquanto entidades puras e máximas, mas que, em contrapartida, fomentam ideias falsas acerca da materialidade humana. Deve ser somada a especulação deste autor, no entanto, duas evidências: o fomento destas ideias falsas se dá a partir de uma operação na consciência humana, que ao alterar a realidade objetiva acaba por transformá-la em dissimulações; estas entidades máximas se relacionam aos interesses de um arranjo burguês.

\footnotetext{
${ }^{6}$ A escolha da mais valia como exemplo entre as adversidades da sociedade capitalista, justifica-se porque ela serve para ilustrar uma das principais bases do poder deste sistema. A mais valia caracteriza-se, pois, pela capitação de um trabalho excedente, que não é pago ao trabalhador e, ao mesmo tempo gera um valor extra (um mais valor) ao capitalista. Este valor é extraído na produção e finalizado no mercado (na esfera da circulação).
} 


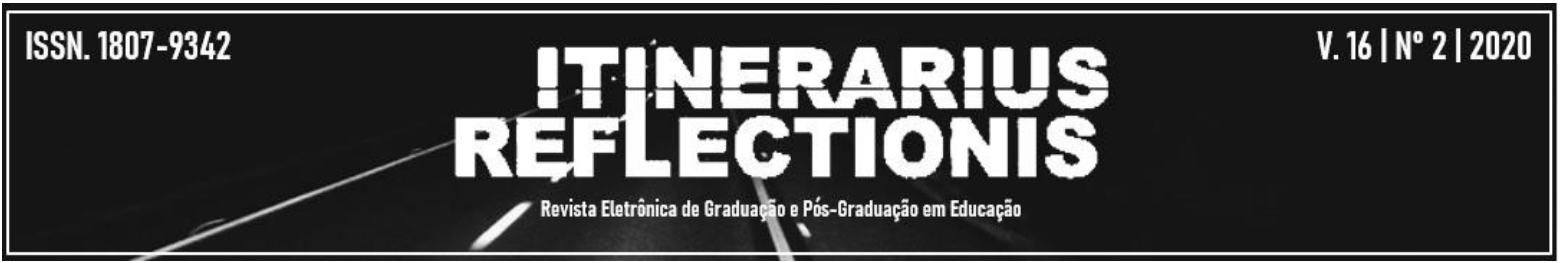

4 GYÖRGY LUKÁCS: APROXIMAÇÕES EXISTENTES ENTRE A CATEGORIA FUNDANTE DO SER SOCIAL E A MAGNITUDE DE UMA CONSCIÊNCIA IDEOLÓGICA

O conceito acerca do papel ideológico em Marx passa a entusiasmar uma gama de outros pensadores, como Lukács. Este não se conforma com uma perspectiva monopolar de ideologia (como em Marx), ou seja, somente uma operação em função dos interesses dominantes - portanto exclusivamente uma ideologia burguesa. Costa (2006) esclarece que o conceito de ideologia em Lukács se desassemelha às orientações marxistas de linha mais tradicional por dois pressupostos: ser ampliado no momento em que se relaciona à base ontológica, a categoria trabalho e, por distinguir-se do conceito de falsa consciência, passando a possuir função importante na reprodução social e, consequentemente, capacitando o ser humano a intervir em seus próprios enfrentamentos cotidianos.

Tendo se amparado na elucidação marxista disposta no Prefácio à Crítica da Economia Política de 1859, onde o fenômeno ideológico da vida social se caracteriza enquanto forma consciente pela qual o ser humano avista seus problemas e busca, através deles, operacionalizar soluções, Lukács (2013, p. 465) considera ser a ideologia, sobretudo, “[...] a forma de elaboração ideal da realidade que serve para tornar a práxis social humana consciente e capaz de agir". Este autor, entretanto, acresce a este conceito o entendimento de que nas sociedades configuradas pela contraposição de classes, os problemas a serem operacionalizados e solucionados são justamente aqueles difundidos pela luta de classes ${ }^{7}$.

O pensamento deste autor se conecta a conceituação de ideologia diante de uma orientação bidirecional no momento em que busca estabelecer, em seus estudos sobre a dialética marxista, o vínculo entre a possibilidade de conhecimento acerca da totalidade histórica e situação de classe ${ }^{8}$. Conde $(1999$, p. 40) salienta que por ser bidirecional em Lukács, a ideologia age tanto diante da burguesia quanto do proletariado, no entanto "é uma força $[. .$.$] que opera no âmbito da falsa ou verdadeira consciência", onde a primeira se vincula$

\footnotetext{
${ }^{7}$ Este embate, ao ser notado, fomenta distintas formas de consciência, que por vez correspondem à ideologia, seja ela representativa dos interesses burgueses ou operários (PINHO, 2013). Vale ressaltar que as formas de consciência são adjetivadas pela distinção, o que significa que elas podem assumir tanto um papel falso, quanto verdadeiro. O dúbio caráter da ideologia, por conseguinte, se apresenta no momento em que esta se reveste tanto pela falsa quanto pela verdadeira consciência, tanto por representações reacionárias quanto revolucionárias, capacitadas a conscientização e ativação da práxis social

${ }^{8}$ Tal possibilidade, a seu ver, é inexistente tanto à burguesia quanto às classes sociais que têm inserção residual na estrutura econômica capitalista. Apenas o proletariado é capaz de ter consciência de classe, pois, em distinção aos demais, se vincula à categoria trabalho (LUKÁCS, 2003).
} 


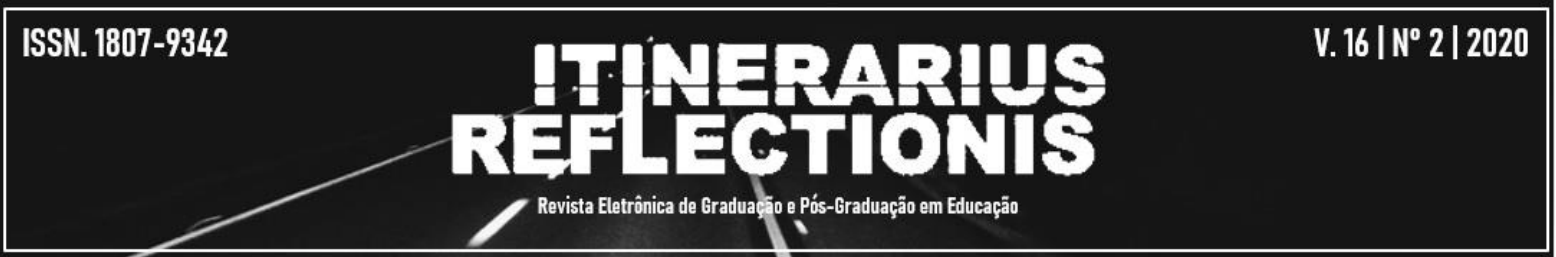

à burguesia, enquanto a segunda ao proletariado, pelo fato deste se dispor à possibilidade de conhecer a totalidade histórica, ao se defrontar com o trabalho manual.

A categoria trabalho é, a partir da ótica lukáciana, o ponto de partida para a compreensão do que o autor convém chamar de ideologia. O ser social, distinto de toda a natureza por pressupor ambos os aspectos naturais (orgânico e inorgânico), se projeta diante da atividade vital teleológica, desta forma se comporta enquanto determinado/estabelecido pela categoria trabalho. Lukács (2013), ao afirmar ser naturalmente, o homem, um ser que responde às condições de reprodução e de existência, impostas pela realidade objetiva, enfatiza o papel do trabalho enquanto práxis fundante, ou seja, enquanto estimulação de novas práxis. Rossi (2016) complementa afirmando que a categoria trabalho concentra, para Lukács, uma análise acerca da dependência ontológica característica aos diferentes compostos sociais.

O processo de trabalho [...] é atividade orientada a um fim - a produção de valores de uso -, apropriação do elemento natural para a satisfação de necessidades humanas, condição universal do metabolismo entre homem e natureza, perpétua condição natural da vida humana e, por conseguinte, independente de qualquer forma particular dessa vida, ou melhor, comum a todas as suas formas sociais (MARX, 2016, 335).

Lukács, como ressalta Pinho (2013), se utiliza desta citação para desenvolver sua linha de raciocínio. A ênfase dada à relação homem-natureza caracteriza a importância oferecida por Lukács ao entendimento do trabalho enquanto um processo onde a subjetividade se converte em objetividade, respeitando, via de regra, o princípio da causalidade ${ }^{9}$. Mostra-se claro, por conseguinte, o trabalho enquanto pressuposto central à humanização do indivíduo, tendo em vista que neste ato ele transforma os objetos da natureza, se afasta do aspecto natural orgânico (característico ao ser biológico) e se imprime enquanto ser social. Acresce, todavia, este autor ao pensamento de Marx, uma segmentação terminológica sobre as ações humanas, distinguindo-as perante posições teleológicas. Pinho (2013), na busca por explicitar estas diferentes posições teleológicas, enfatiza que é natural, no pensamento lukáciano, haver caráter teleológico em toda atividade humana. As ações teleológicas, representativas do

\footnotetext{
${ }^{9}$ O trabalho é um processo onde a subjetividade (uma elaboração ideal) se converte em objetividade (em realidade). Neste processo, por um lado, a subjetividade pressupõe a objetividade a ser transformada e, portanto, tem que respeitar as suas leis causais. Porém, por outro lado, esta objetividade não determina, de modo absoluto, a ação da subjetividade. A objetividade apresenta um campo de possíveis transformações, dentro do qual a subjetividade escolhe entre as alternativas postas o caráter da transformação a ser operado. E esta transformação só se efetiva através da ação da subjetividade que optou por determinada operação. Para Lukács, portanto, a objetividade se apresenta de forma múltipla e complexa, não podendo ser absoluta sobre a subjetividade, pois isso invalidaria parcialmente o princípio da causalidade.
} 


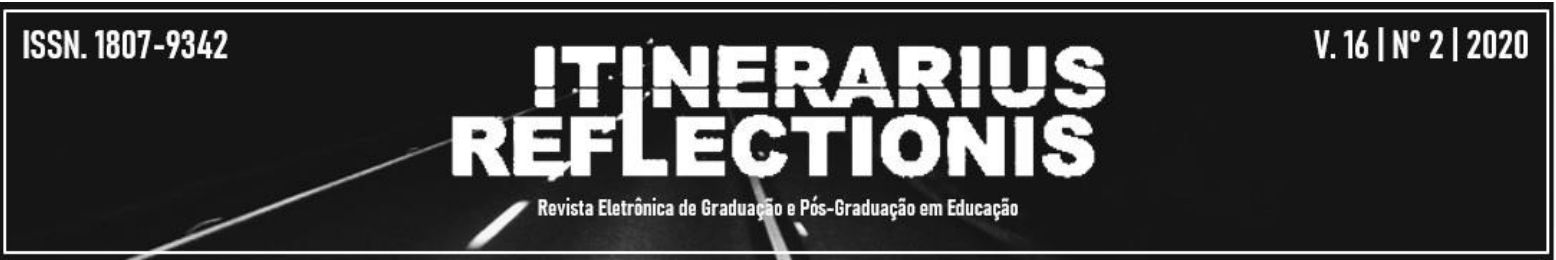

pensamento de Lukács, se caracterizam ora pelo sentido laboral, ora extra-laboral. São assim apresentadas por Pinho (2013, p. 82):

\begin{abstract}
As atividades laborativas - precedidas por um momento ideal e por uma decisão entre alternativas - têm como finalidade movimentar e transformar objetos cujos nexos causais são dados pelas leis da natureza, que atuam independentemente da organização da sociedade humana. De modo distinto, as atividades extra-laborativas - que são também precedidas por uma prévia-ideação e por uma decisão entre alternativas, têm como objetivo a organização da vida humana, mediata ou imediatamente, a manutenção ou a destruição desta organização, que só pode ser efetivada através do comportamento dos homens reais (grifos meus).
\end{abstract}

O que excepcionalmente distingue ações teleológicas laborais às extra-laborais é o fato de que o segundo grupo, por se efetivar unicamente em função do comportamento humano em prol de uma adequação da vida social, fomenta o aparecimento de outras posições teleológicas, imbuídas de uma nova configuração ao comportamento humano. A ação teleológica extra-laboral, assim sendo, possui uma pretensão ideal, um ser social complexo e, consequentemente, um menor grau de conhecimento sobre a objetividade vislumbrada. Em contrapartida, a ação teleológica laboral se efetiva em função de uma objetividade para além do mundo humano-social, ou seja, independe do homem. Isso faz com que ela possua uma pretensão real, um ser natural (não social) pouco complexo e uma maior possibilidade de compreensão acerca da objetividade vislumbrada (PINHO, 2013) ${ }^{10}$.

A ótica lukáciana, como se vê, compreende haver caráter teleológico em toda atividade humana. Há de se entender, todavia, que o caráter teleológico é qualitativamente distinguido diante da presença do sentido laboral. Fica claro, portanto, que enquanto as ações teleológicas laborativas estabelecem uma relação direta com a objetividade natural, fazendo com que todo o conhecimento descoberto se possibilite em função desta relação, no âmbito das "formas superiores da prática social" (nas ações teleológicas extra-laborativas) a objetividade não se alia à natureza, mas ao complexo social. Neste último caso, Vaisman e Fortes (2014, p. 122) evidenciam que "as ações humanas não visam apenas o pôr em movimento de nexos causais da natureza, mas visam acima de tudo a consciência de outras

\footnotetext{
${ }^{10}$ Esta explanação, acerca do caráter teleológico da ação humana, aliada a uma especulação sobre o processo histórico da humanidade, aclara uma destituição do homem, cada vez maior, para com a vida orgânica em função do surgimento de um ser social. As atividades extra-laborativas, em compasso a este conjunto, surgem pela necessidade de manutenção do comportamento humano, assim como pela projeção de práxis futuras. As antecipações mentais destas atividades, por conseguinte, podem se caracterizar enquanto ideologias, tendo em vista a intuição prévia que estas exercem sobre o modelamento comportamental humano dentro de um contexto social.
} 


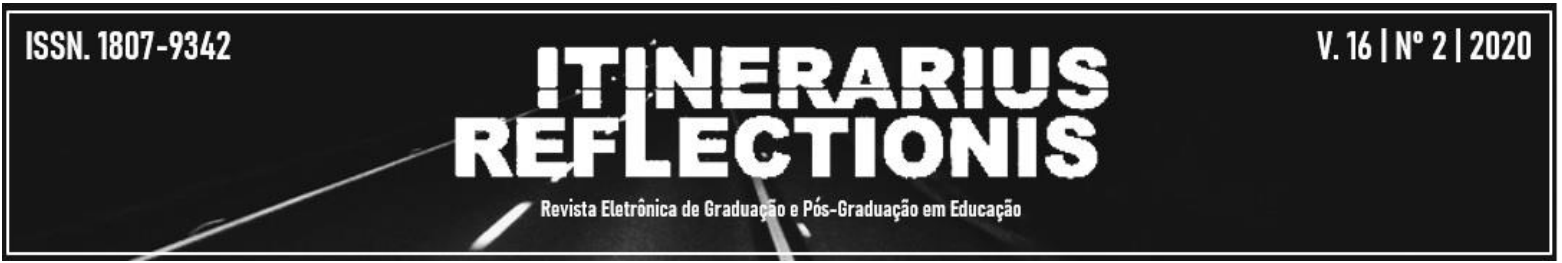

individualidades", portanto a objetivação se relaciona à capacitação de decisões e comportamentos, a nível da consciência humana, para a obtenção determinações almejadas.

Nas ações teleológicas extra-laborativas, antes mesmo de haver uma transformação direta dos nexos causais naturais, ou seja, uma mudança na materialidade do mundo da objetividade natural, existe intento à consciência dos indivíduos, na tentativa de exortá-los a assumir determinadas decisões e comportamentos. Concomitantemente, como assegura Pinho (2013), é ideológica a prévia intuição que estas ações teleológicas exercem sobre o modelamento comportamental humano, pois muito antes de inferir sobre a objetividade natural, o ser social tem, por meio de suas ideias, consciência sobre os principais conflitos sociais de seu período histórico, se capacitando a dirimi-los, enfrentá-los, e sobre eles intervir, propondo direcionamento a uma nova práxis social (VAISMAN; FORTES, 2014).

A ideologia em Lukács independe de um caráter falso ou verídico, ela é dada pela eficácia, pela transformação da realidade e pela aprovação de processamento dessa transformação ${ }^{11}$.

O prisma ontológico se alimenta de uma ação operativa sobre a própria realidade social. A ideologia sob o enfoque deste prisma consiste em analisar as intersecções que o ser social estabelece com sua vida material.

A concepção de ideologia em Lukács está intimamente articulada à função social que um pensamento exerce no âmbito dos conflitos sociais. [...] Quando o conflito social apresenta-se como problema vital para a sociedade, no qual as classes travam lutas sociais sob os mais diversos aspectos, penetrando até o íntimo das individualidades, a ideologia, então, se expressa como instrumento ideal de luta que serve aos embates entre grupos humanos com interesses antagônicos (COSTA, 2006, s.p., grifo meu).

Fica claro que é da consciência, como considera Conde (1999), que Luckács passa a orientar sua acepção de ideologia, entretanto é importante evidenciar que é a partir da função social aliada ao caráter humano da ação teleológica extra-laborativa, aquela vinculada as "formas superiores da prática social", que o conflito social pode ser configurado enquanto luta de classe. A ação teleológica extra-laborativa, assim sendo, se caracteriza por um cenário propício ao aparecimento da luta de classes enquanto conflito social determinante, somente

\footnotetext{
${ }^{11}$ Destarte qualquer ideia pode vir a ser uma ideologia, e mesmo aqueles que se enxergam enquanto ideólogos devem operar socialmente para tornarem em ideologias as suas prévias formulações. A intervenção direta sobre a realidade social é o que confere sentido ontológico à ideologia, é o que faz transcender a perspectiva lógicognosiológica até então, aos tempos de Lukács, dominante nos pressupostos filosóficos, em que o papel ideológico se restringe a "um problema do saber" (PINHO, 2013).
} 


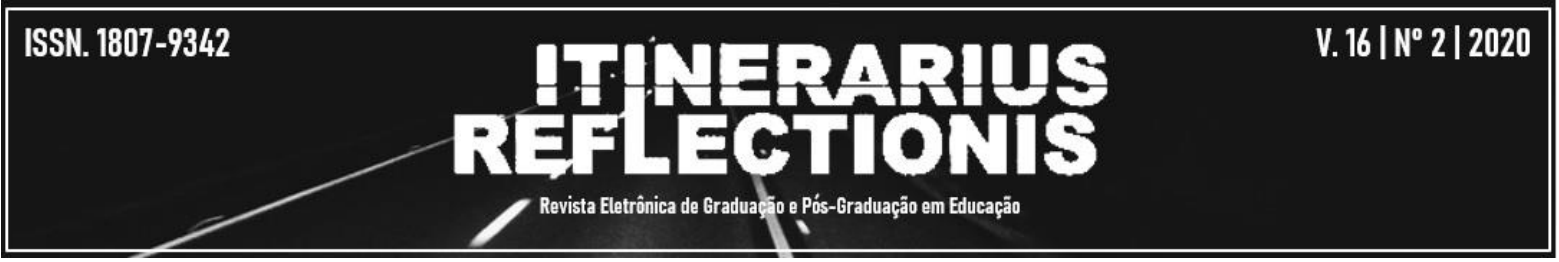

nelas os fundamentos últimos destes conflitos devem ser examinados a partir do desenvolvimento econômico (LUKÁCS, 2013). Aí se encontra a importância de aliar o caráter teleológico da ação humana (que percorre um caminho em direção à destituição da vida orgânica e instituição do ser social) ao processo histórico da humanidade, pois "a ideologia se manifesta de modo diferenciado no decurso da história" (VAISMAN; FORTES, 2014, p. 121).

Para finalizar o entendimento de ideologia em Lukács, é importante compreender que a concepção de ideologia restrita a ação teleológica extra-laborativa "é quase que uma força 'espiritual', [...] e que essa força se revela para a revolução e depende da formação da consciência de classe proletária para imprimir as transformações" (CONDE, 1999, p. 42). Eis a ideologia proletária, caracterizada pela verdadeira consciência e compreendida enquanto fundamental para que o ser social dirima os conflitos surgidos no interior da sociedade de classes.

\section{ESFORÇO DE SÍNTESE: A GRANDEZA DA IDEOLOGIA EM LUKÁCS E O PENSAMENTO EDUCACIONAL}

Certamente, o maior avanço propiciado por Lukács com relação à categoria ideologia remete-se à articulação desta à categoria fundante do ser social (o trabalho), deixando de limitá-la tão somente à ação teleológica laborativa e avançando a partir da dupla possibilidade calcada pela ideologia no âmbito da ação teleológica extra-laborativa.

Se a objetivação, do ponto de vista da ação teleológica extra-laborativa se relaciona à capacitação de decisões e comportamentos, em nível da consciência humana, para a obtenção de determinações sensibilizadas à função social, passa a se tornar evidente a alternativa de um papel ideológico como fomento ao reconhecimento dos interesses sociais coletivos, comuns e universais.

Esta alternativa tem consequente implicação na consolidação de uma intencionalidade educativa sensibilizada ao desenvolvimento livre da capacidade humana, uma vez que por meio da ação teleológica extra-laborativa, ou seja, cuja objetivação não se encontra grávida de sentido exclusivamente dado à natureza, muito menos à necessidade de manutenção do comportamento humano, mas ao complexo social, às "formas superiores da prática social", a negação (e consequente superação) do completo estado de alienação, presumidamente enfático à realidade educacional atual, torna-se possível. 


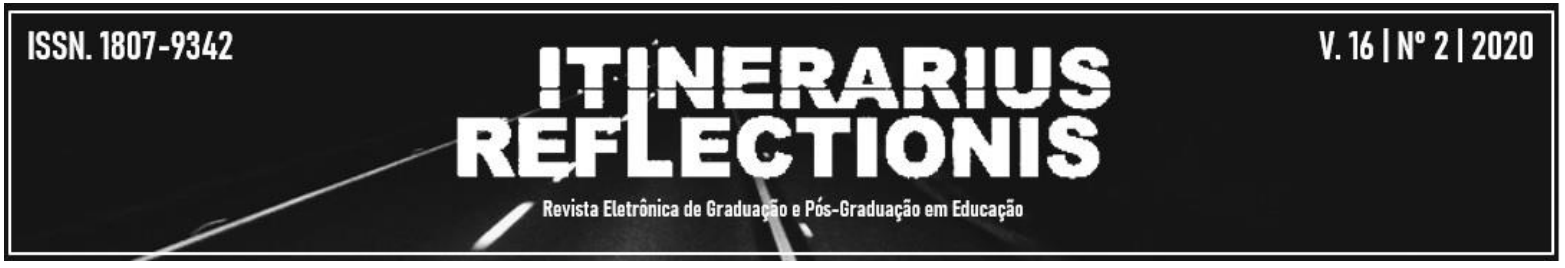

Destarte, a ação teleológica extra-laborativa enquanto princípio educativo, ao pressupor a negação de uma ideologia hegemônica, tanto no que concerne a realidade material, quanto no campo da consciência, também apreende sua consequente substituição por uma ideologia atinente à transformação da realidade material, e também da consciência em prol desta transformação, para fins de enriquecimento social das forças humanas, tal como previa a escola socialista, e por consequência como acata os princípios de uma teoria verdadeiramente crítica da educação.

\section{REFERÊNCIAS}

CHAUÍ, Marilena. O que é ideologia. 26. ed. São Paulo: Editora Brasiliense, 1988.

CODATO, Adriano. O conceito de ideologia no marxismo clássico: uma revisão e um modelo de aplicação. Política \& Sociedade, v.15, n.32, p.311-331, jan/abr. 2016.

CONDE, Dirceu Cleber. Dois grandes períodos da concepção de ideologia. Working Papers em Linguística, v.3, n.1, 1999.

COSTA, Gilmaísa Macedo da. Lukács e a ideologia como categoria ontológica da vida social. Revista Urutágua, n.9, n.p., abr/jul, 2006.

DUARTE, Newton. Os conteúdos escolares e a ressurreição dos mortos: contribuição à teoria histórico-crítica do currículo. Campinas: Autores Associados, 2016.

O currículo em tempos de obscurantismo beligerante. Espaço do Currículo, v.11, n.2, p.139-145, mai./ago. 2018.

GORENDER, Jacob. Apresentação. In: MARX, Karl. O Capital: crítica da economia política. Livro I: o processo de produção do capital. Versão eletrônica. São Paulo: Boitempo Editorial, 2013.

LUKÁCS, György. Existencialismo ou marxismo. São Paulo: Editora Ciências Humanas Ltda., 1979.

História e consciência de classe: estudos sobre a dialética marxista. São Paulo:

Martins Fontes, 2003.

Para uma Ontologia do Ser Social II. São Paulo: Boitempo Editorial, 2013.

MANACORDA, Mario Alighiero. A "pedagogia" marxiana. In: . Marx e a pedagogia moderna. Campinas: Editora Alíneaz, p.31-114, 2007.

MARX, Karl. O capital: crítica da economia política. Livro I: o processo de produção do capital. 34. ed. Rio de Janeiro: Civilização Brasileira, 2016. 


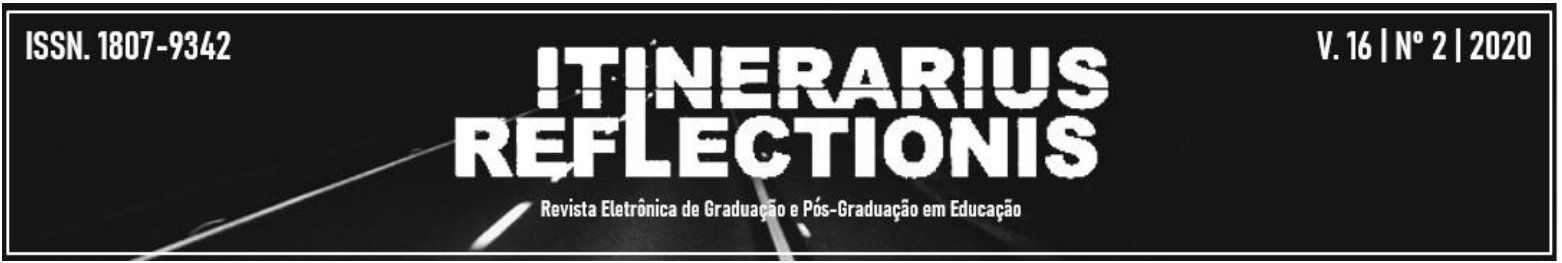

MARX, Karl; ENGELS, Friedrich. A ideologia alemã. São Paulo: Boitempo Editorial, 2007. Manifesto do partido comunista. Porto Alegre: L\&PM, 2017.

PINHO, Maria Teresa Buonomo de. Ideologia e formação humana em Marx, Lukács e Mészáros. Tese (Doutorado em educação brasileira). Fortaleza: Universidade Feral do Ceará - Faculdade de Educação, UFC/FACED, 2013.

ROSSI, Rafael. Educação e ideologia: uma análise ontológica. Filosofia e Educação, v.8, n.2, p.169-193, jun/set. 2016.

ROSSLER, João Henrique. A educação como aliada da luta revolucionária pela superação da sociedade alienada. In: DUARTE, Newton (Org.). Crítica ao fetichismo da individualidade. Campinas: Autores Associados, 2004.

SAVIANI, Dermeval. Escola e democracia: teorias da educação, curvatura da vara, onze teses sobre educação e política. 30. ed. Campinas: Autores Associados, 1995.

VAISMAN, Ester; FORTES, Ronaldo Vielmi. A politicidade no pensamento tardio de György Lukács. Estudos Políticos, v.5, n.1, p.118-132, dez. 2014. 